\title{
CORRECTION
}

\section{Correction to: Response to "Pay Attention to Blood Pressure and Oxygen Supply for Neurocritically III Patients: Each Pathology Deserves a Specific Treatment"}

Jaana Humaloja ${ }^{1 *} \mathbb{D}$, Erik Litonius ${ }^{2}$ and Markus B. Skrifvars ${ }^{1}$

(c) 2021 Springer Science+Business Media, LLC, part of Springer Nature and Neurocritical Care Society

\section{Correction to: Neurocrit Care} https://doi.org/10.1007/s12028-021-01213-4

This article was originally published electronically on the publisher's internet portal (currently SpringerLink) on March 22, 2021 with open access.

The copyright of the article changed on April 2021 to (c) 2021 Springer Science+Business Media, LLC, part of Springer Nature and Neurocritical Care Society and the article is forthwith distributed under the terms of copyright.

\section{Author details}

${ }^{1}$ Department of Emergency Care and Services, University of Helsinki and Helsinki University Hospital, Helsinki, Finland. ${ }^{2}$ Division

of Anesthesiology, Department of Anesthesiology, Intensive Care

and Pain Medicine, University of Helsinki and Helsinki University Hospital, Helsinki, Finland.

\section{Publisher's Note}

Springer Nature remains neutral with regard to jurisdictional claims in published maps and institutional affiliations.

Published online: 17 May 2021

*Correspondence: jaana.humaloja@outlook.com

${ }^{1}$ Department of Emergency Care and Services, University of Helsinki and Helsinki University Hospital, Helsinki, Finland

Full list of author information is available at the end of the article

The original article can be found online at https://doi.org/10.1007/ s12028-021-01213-4.

\section{Springer}

